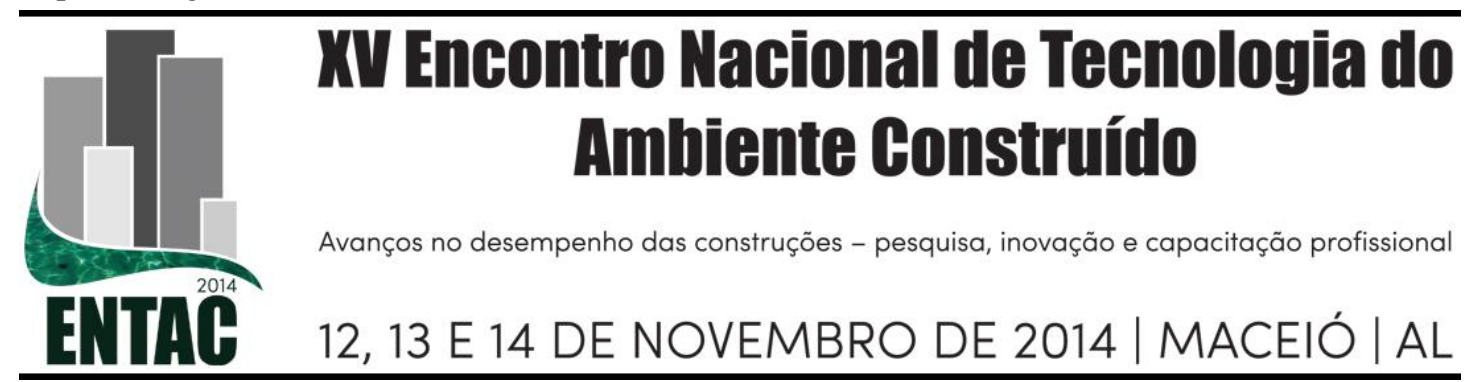

\title{
REFLEXÕES SOBRE A FORMAÇÃO DE UM NOVO LUGAR: AS HABITAÇÕES DE INTERESSE SOCIAL DO PROGRAMA MCMV
}

\section{ONGARO, Daniella Fonseca Zanotti (1); ABDALLA, José Gustavo Francis (2)}

(1) Universidade Federal de Juiz de Fora, e-mail: daniellaongaro@yahoo.com.br (2) Universidade Federal de Juiz de Fora, e-mail: gustavofrancis@ig.com.br

\begin{abstract}
RESUMO
A Política Nacional de Habitação propõe a universalização do acesso à moradia digna a todos os cidadãos, conforme publicado pelo Plano Nacional de Habitação - PlanHab - em 2010. Contudo, verifica-se que os programas habitacionais brasileiros priorizam os parâmetros econômicos e de produção, não valorizando as questões sociais e culturais dos futuros moradores dos empreendimentos. Dessa forma, pode-se constatar a dificuldade no estabelecimento de um senso de lugar e de habitar por parte dos moradores. Esse trabalho considera os conflitos de formação do território como parte integrante do processo para a formação de um novo lugar. Por meio de uma revisão bibliográfica sistematizada de quatro categorias geográficas espaciais: espaço, lugar, paisagem e território; foram encontrados dezessete artigos, sendo destacados os cinco principais em função da dimensão do texto. O objetivo envolve delimitar o território da recomposição social do agrupamento de famílias que mudaram para um novo conjunto habitacional. Observa-se que há um espaço intermediário que permite a redefinição de identidade entre os moradores que vieram de diferentes lugares e culturas. No artigo conclui-se que ocorreu um processo de desterritorialização e está em curso a reterritorialização da comunidade constituída pelo Programa Minha Casa Minha Vida deste estudo. Esta pesquisa pretende colaborar com a discussão sobre o resultado da produção das habitações de interesse social no Brasil, destacando a importância em considerar os aspectos sociais, além dos técnicos, também como parte integrante dessa problemática, contribuindo para a constituição de empreendimentos que sejam socialmente sustentáveis.
\end{abstract}

Palavras-chave: Categorias Geográficas Espaciais, Habitação de Interesse Social, Programa Minha Casa Minha Vida, Sustentabilidade Social.

\begin{abstract}
The National Housing Policy proposes universal access to adequate dwelling for all citizens, as shown by the national plan (PlanHab) in 2010. Although, it appears that Brazilian housing programs prioritize economic and productive parameters, not taking care about social or cultural issues of future residents in housing complex. These concerns can demonstrate the difficulty in establishing a sense of place and reside by the locals. This paper have as goals discuss about struggles of territory's development as part of process in establishiment of new areas. To support this work sheet, were reviews in several consolidate and substantial researches, those conceptions: space, places, territory and landscape. The transitions of families to their new home place, representing a reinstatement of collective life way. Is viewed that places between their house's and neighborhood allowing a redefinition of plenty of different cultures and identities. This paper point out there are a process of deterritorialization and reterritorialization is an ongoing community in development. This research intends to collaborate with the discussion about production of social housing in Brazil, highlighting the importance of considering the social aspects, beyond the technical, contributing to the creation of dwelling that are socially sustainable.
\end{abstract}

Keywords: spatial geographic categories; social housing; Program "Minha Casa, Minha Vida"; social sustainability. 


\section{INTRODUÇÃO}

A Política Nacional de Habitação propõe a universalização do acesso à moradia digna a todos os cidadãos, conforme publicado pelo Plano Nacional de Habitação - PlanHab em 2010. Contudo, verifica-se que os programas habitacionais brasileiros priorizam os parâmetros econômicos, utilizando soluções de produções para serem realizadas no curto prazo de tempo e baixo custo construtivo, aparentemente, não valorizando as outras questões sociais e culturais que envolverão os futuros moradores dos empreendimentos.

Este artigo considera a dimensão social como parte integrante e necessária das características sustentáveis de um determinado empreendimento habitacional de interesse social, onde "a questão habitacional não se resume a acesso ao abrigo. Está ligada às condições de fixação do homem ao local de moradia, tanto no sentido da apropriação dos espaços quanto no da subsistência familiar e das relações de vizinhança" (PALERMO, 2009). Dessa forma, faz-se necessário considerar a dimensão subjetiva do ambiente construído (LEITÃO, 2002) a fim de que se possam obter resultados mais satisfatórios na produção das habitações brasileiras, principalmente as relacionadas ao interesse social. Muito além de abrigo, o ambiente construído representado pelas habitações, tende a constituir um lugar portador de história (tempo), um lar (vivência), apresentando significados e valores (cultura e identidades).

O presente artigo é decorrente de uma pesquisa em andamento, tendo como título provisório: “A Sustentabilidade Social nas Habitações de Interesse Social: estudo de caso sobre a relação entre violência e lugar nos empreendimentos Minha Casa, Minha Vida". Contudo, direcionada para uma natureza possível de ser observada em empreendimentos localizados em diversas cidades brasileiras. $O$ interesse se deu, principalmente, em função de notar a origem e expressividade das ações violentas ocorridas no município em estudo durante o ano de 2013, bem como a verificação da situação dos empreendimentos habitacionais dentro do Programa Minha Casa, Minha Vida (PMCMV). Eles apresentam diversos problemas sociais, arquitetônicos e urbanísticos. Esse artigo é parte do contorno teórico e conceitual da dissertação. Aqui, busca-se apresentar a identificação do território da recomposição social do agrupamento de famílias que mudaram para um novo conjunto habitacional, por meio da análise acerca de algumas categorias espaciais. É uma pesquisa teórica de caráter qualitativo, de observação direta, sob a ótica da sustentabilidade social, utilizando-se como suporte o espaço, o lugar, a paisagem e o território.

O artigo foi produzido em três etapas: (1) revisão bibliográfica sistematizada, (2) visitas exploratórias, (3) entrevista semiestruturada. Inicialmente, foi realizada uma busca online por artigos nacionais que abordam a temática da pesquisa, por meio de consultas aos periódicos disponíveis nas seguintes bases de dados: Periódicos Capes, Scielo e LILACS. Utilizou-se como descritores os seguintes termos: categorias espaciais; habitação de interesse social; Programa Minha Casa, Minha Vida; e sustentabilidade social; onde cada termo foi inserido separadamente. Foram priorizados somente artigos completos, sendo selecionados 17 desses.

Complementarmente à revisão bibliográfica, uma consulta não sistematizada foi realizada, por meio da leitura das referências presentes em alguns artigos selecionados. Paralelamente à realização dessa pesquisa bibliográfica, foram feitas visitas exploratórias, procurando-se a apreensão de impressões do lugar e a obtenção e/ou constatação de dados técnicos in loco do ambiente construído em estudo, incluindo seu contexto social. Também foi realizado uma entrevista semiestruturada com a 
coordenadora do Núcleo de Projetos Sócio Habitacionais da Empresa Regional de Habitação do Município (EMCASA).

Essa pesquisa destaca a relevância em se constituir empreendimentos habitacionais que estabeleçam uma condição de âmbito urbano, ou seja, aquela em que as promoções de novos ambientes construídos devem estar inseridas adequadamente nas cidades, sendo responsáveis por fazer com que seus moradores sintam-se parte de um lugar da cidade, proporcionando, entre outros aspectos, a determinação da cidadania dos indivíduos (VIGLIECCA, 2014). Conforme divulgado pelo Ministério das Cidades (2010), esse é um dos aspectos que permite colaborar para a fixação das populações beneficiadas nos empreendimentos. Assim, entende-se que a ausência do atendimento desse aspecto pode contribuir para que os moradores não se identifiquem com as novas moradias, dificultando o estabelecimento de vínculos com o lugar. $O$ artigo trata dessas questões uma vez que considera por teorias a que tratamos no decorrer do texto, para as habitações de interesse social e de espacialidade similar a essas, a existência de um espaço intermediário (entre o interior doméstico e a cidade) que possibilita a percepção de construções de novas relações e ordenamento das identidades entre os moradores.

\section{FUNDAMENTAÇÃO TEÓRICA}

Como suporte teórico, recorre-se a um campo disciplinar da Geografia, a fim de enriquecer e ampliar o entendimento sobre os conceitos de espaço, lugar, paisagem e território; sendo destacados os pertencentes à corrente humanista da geografia, frutos de processos de renovação da disciplina, ocorridos a partir da década de 70 , onde foram desenvolvidos trabalhos complementados por disciplinas, como a antropologia, a sociologia, a psicologia, entre outros. Conforme Holzer (1997), nesse campo da geografia, as análises das ações e produtos humanos passam a ser consideradas nas abordagens de temas geográficos, apresentando estudos que vão além da perspectiva científica cartesiana. Nesse campo tem-se como aporte filosófico a fenomenologia que considera, em suas análises, os aspectos do espaço vivenciado.

Conforme Calisto (2006), encontra-se na categoria espaço as características da relação entre o homem e a natureza. Segundo Holzer (2012), o espaço refere-se às questões da relação entre o homem e o mundo, ou seja, à existência do homem na Terra. Caracterizado como primitivo, no sentido de antecedente, prévio, o espaço é estabelecido por meio de sua apropriação pelo homem através da determinação das distâncias, direções e estabelecimento de marcos referenciais. Essas determinações produzem os espaços construídos, aqui tratados como ambiente construído, caracterizados por um conjunto de intervenções que modificam o ambiente natural ao longo do tempo.

A geografia humanista introduz estudos relacionados à vivência no espaço, considerando, por exemplo, aspectos referentes à situação do homem no espaço, aprimorando as reflexões sobre o mesmo; bem como considerando a percepção humana como um dos instrumentos de análise das questões espaciais (CALISTO, 2006). Esses espaços (vividos) são compreendidos tendo-se em consideração também os aspectos simbólicos, sentimentais e relacionados às experiências dos indivíduos, ou seja, também como espaço relacionado à prática social (HORA NETO e QUEIROZ, 2010). Ao tratar das relações entre espaço e lugar, Tuan (2013) afirma que o espaço é caracterizado como abstrato, indiferenciado e desprovido de valor. Quando o vínculo com o espaço é iniciado, o mesmo se transforma em lugar, ou seja, para Tuan (2013), o lugar é familiar e dotado de valor. 
O conceito de lugar caracteriza-se como o espaço vivido dotado de significado, indo além da compreensão do espaço produzido, uma vez que considera os sentidos e as ideias dos indivíduos que vivem em determinado espaço (HORA NETO e QUEIROZ, 2010). Cabral (2007) afirma que a constituição do lugar se dá por meio de diversas experiências relativas à existência humana, entre elas: "viver, habitar, utilizar, consumir, trabalhar". O lugar pode apresentar-se em diferentes escalas, por exemplo: desde, representando uma escala menor, através da constituição da moradia, sendo essa, lugar gerador de significados; bem como pode ser representado pelo bairro, por meio da sociabilidade.

Mello (2012) reforça o discurso, acima colocado, ao indicar o que para ele é percebido comumente nas comunidades e periferias, por exemplo: a rua como a extensão da casa é uma situação verificada na convivência e nas atividades desenvolvidas nos espaços coletivos de empreendimentos habitacionais, sendo um dos aspectos que contribuem para a apropriação do espaço, percepção e caracterização do território, interação comunitária e criação de valores identitários e de fortalecimento cultural levando-se à territorialidade, tudo contribuindo para a formação do lugar. Entretanto, o tempo desempenha um relevante papel para que, efetivamente, o lugar seja constituído. Oliveira (2012) e Tuan (2013) destacam essa ligação entre o espaço e o tempo, apontando que o significado de determinado lugar cresce ao longo dos anos, à medida que são incorporados sentimentos para com os mesmos, indicando que a experiência, conquistada diariamente, contribui para se sentir num lugar.

Em sua atuação profissional, o arquiteto contribui para a constituição de lugares uma vez que o mesmo busca, por meio de considerações sobre a cultura, hábitos, necessidades, etc., produzir ambientes que respondam ao desejo dos indivíduos, procurando, segundo Tuan (2013), "dar-lhes forma simbólica". Ao descrever alguns aspectos de lugar, Relph (2012), destaca a função de arquitetos e planejadores como atores responsáveis pela tentativa de produzir lugares, pois, segundo ele, os lugares são efetivamente constituídos somente a partir da vivência dos indivíduos nos mesmos, visto que são os indivíduos quem estabelecem as atividades e desenvolvem os significados. Os arquitetos e planejadores proporcionam a construção de ambientes e infraestrutura que facilitam a criação desses lugares.

A paisagem, tal como o espaço e o lugar, também apresenta-se como uma das bases da geografia humanista, ao considerar o envolvimento do homem com o mundo (CABRAL, 2000). Segundo Cabral (2007), o conceito de paisagem vincula-se à percepção do espaço, ou seja, está relacionado à forma de visualização e de composição do mundo; cujo processo envolve a organização das informações percebidas e as atribuições de sentido. A paisagem "traduz-se num campo de visibilidade e, ao ser oferecida a nossa percepção e a nossa experiência, converte-se num campo de significação individual e coletiva", (CABRAL, 2007), implicando na apresentação de perspectivas diversas (LOPES, 2012). A paisagem reporta-se para o mundo, cuja composição se dá por meio das relações entre os indivíduos (HOLZER, 1997). Segundo Cabral (2007), paisagem é considerada nas situações em que aspectos visuais, somados à sua dimensão simbólica, adquirem relevância na análise das relações do homem com o espaço. Sendo assim, a paisagem, por um lado, é uma percepção individual e, por outro lado, senso comum da sociedade em relação ao contexto da natureza (dada ou construída) e visão de mundo que o homem tem para refletir, interpretar e a representar.

A observação dessas relações (homem/espaço) também contribui para a compreensão do conceito de território uma vez que, segundo Raffestin (1993) apud Lopes (2012), o território é constituído a partir do espaço, onde verifica-se a apropriação desse pelo 
homem. Segundo Lopes (2012), questões relacionadas ao controle e à gestão do espaço estão associadas às relações de poder, as quais são observadas em uma análise territorial, onde é considerada a forma como o homem utiliza o espaço, ou seja, o territorializa. Haesbaert (2001) sugere três diferentes sentidos para a definição de território, são eles:

\footnotetext{
“1) jurídico-política: a mais difundida, onde o território é visto como um espaço delimitado e controlado, por meio do qual se exerce um determinado poder, na maioria das vezes visto como o poder político do Estado;

2) cultural (ista): prioriza a dimensão simbólico-cultural, mais subjetiva, na qual o território é visto sobretudo como o produto da apropriação/valorização simbólica de um grupo sobre seu espaço;

3) econômica: bem menos difundida, enfatiza a dimensão espacial das relações econômicas no embate entre classes sociais e na relação capital-trabalho."
}

Em conformidade com o objetivo desse artigo, destaca-se a dimensão cultural, também chamada de simbólica por Haesbaert (2001), a qual enfatiza a existência de um controle simbólico sobre o espaço onde vivem os grupos sociais. Esse controle se dá por meio da constituição de uma identidade territorial (HAESBAERT, 2001). Souza e Pedon (2007) ressaltam também a necessidade do entendimento dessas relações de afetividade e de identidades entre determinado grupo social e seus espaços de vivência.

Podendo apresentar diferentes dimensões (política, cultural, econômica), a territorialidade relaciona-se à maneira de apreensão e/ou apropriação de determinado espaço em utilização pelas pessoas, sendo caracterizada pela organização das pessoas no espaço e pela forma como as pessoas constroem o lugar (HAESBAERT, 2004). Para que ela seja melhor compreendida, faz-se necessário o entendimento das relações sociais e culturais que as pessoas estabelecem com os lugares (BONNEMAISON (1981) apud HOLZER (1997)). Ao utilizar a territorialidade como estratégia para a determinação do controle, o indivíduo (ou grupo) adquire poder sobre determinado espaço, por meio da tentativa de influenciar outros indivíduos (SACK (1983) apud HOLZER (1997)).

Entretanto, o território está submetido à diversos processos, os quais podem ser responsáveis por desfazê-lo, deixando de existir as relações, apropriações e vivências sobre determinado espaço. Essa perda do território é chamada desterritorialidade; e quando há a busca da territorialidade em novos territórios, configura-se a reterritorialidade, onde novas identidades são construídas baseadas em características do antigo território, ou seja, em um novo espaço, a princípio desconhecido, inicia-se a tentativa de estabelecer a construção de um novo território, na maioria das vezes, baseando-se em características de antigos territórios (CORREA apud SOUZA E PEDON, 2007). Por fim, há que se salientar que neste artigo não se está considerando os grupamentos humanos que mantêm identidades e até territorialidades sem o suporte físico coeso e contínuo, como também, reconhece que os indivíduos levam consigo valores adquiridos em outros lugares em suas migrações para novas terras, onde se formarão novas concepções, desde as relações ecológicas e sistêmicas até culturais, consequentemente, sentimentais e, assim, de lugares. 


\section{O OBJETO DE ESTUDO EM DEBATE}

O objeto de estudo desse artigo é um empreendimento de interesse social pertencente à primeira fase do Programa Minha Casa, Minha Vida (PMCMV) localizado em uma cidade da região sudeste brasileira. Por ser o primeiro a ser implementado na cidade, esse empreendimento apresenta um maior histórico de ocupação em comparação a outros existentes, o que permite verificar os transtornos já consolidados.

Caracterizado como Condomínio, o empreendimento apresenta uma única tipologia: trinta e dois sobrados, cada um possuindo quatro unidades habitacionais, totalizando cento e vinte e oito. Possui também portaria, área de lazer, área para depósito de lixo, parque infantil e quatro ruas internas. Localizado na região sul do município, é pertencente à uma área de fronteira urbana e distancia-se do centro em, aproximadamente, oito quilômetros (PJF, 2000). Desde sua inauguração, em 2011, o Condomínio confronta-se com diversas situações relacionadas à precariedade de suas edificações, muitas delas apresentando patologias diversas, resultando em abandonos e consequentes invasões.

O critério de seleção das famílias beneficiadas se deu por meio de um sorteio das pertencentes ao Cadastro Único. Segundo a coordenadora do Núcleo de Projetos Sócio Habitacionais da Empresa Regional de Habitação do município (2014), essa é a alternativa atual encontrada para dar resposta à elevada demanda em relação à oferta de habitações. Esse fato colabora para aproximar indivíduos provenientes de diversos bairros do município, os quais apresentam grande diversidade cultural, ideológica e comportamental.

O Condomínio também enfrenta a inadequação familiar, visto que há relatos de famílias constituídas por até treze pessoas residindo na mesma unidade habitacional. A situação dos imóveis é crítica, uma vez que são verificadas, além das invasões anteriormente citadas, aluguéis e repasses. Há relatos e constatações de ocorrência de variados tipos de violência, sejam elas internas ou externas ao ambiente doméstico. Brigas de gangues, depredação de alguns imóveis e dos espaços comuns dos empreendimentos, tráfico de drogas, entre outros, são alguns exemplos. Essas condutas ilícitas são teoricamente reflexos da tentativa de "territorializar o espaço", buscando o controle e o poder de um grupo ou indivíduo sobre os outros (o eu e o não eu presente em todos os seres vivos).

O contexto exposto acima certamente afasta o "sentimento de bairrofilia", discorrido por Mello (2012), ao enfatizar que a moradia proporciona a sensação de "apego, pertencimento, desenvoltura, filiação e bem-estar", características essas não observadas nos moradores do Condomínio em estudo. A ausência de vínculo com o espaço vivido é percebida por meio da verificação de um enorme descuido relacionado aos espaços de uso coletivo, evidenciando um espaço ausente de significados e valores, dificultando a efetiva constituição de lugares. O comportamento dos moradores vai ao encontro da colocação de Tuan (2013), ao relatar sobre o sentimento dos indivíduos que não vivem em moradias planejadas por elas, onde o ambiente construído não traduz o ideal dos seus moradores, corroborando para o afastamento dos mesmos.

A pesquisa, ao que parece até este momento, nos faz levantar a hipótese de que os conflitos sociais são resultantes da falta de identidade entre os moradores e as novas moradias. Mello (2012) afirma que a conduta dos indivíduos é influenciada pelo ambiente que o envolve, seja o mesmo "físico, social ou imaginário". No caso do Condomínio, esse fato pode ser percebido por meio da questão paisagística do território, entre a cidade e o lugar da unidade arquitetônica, onde não existe a contribuição para a formação cidadã dos moradores, resultando na ausência de integração desses com o 
bairro e repercutindo na percepção negativa para o espaço. Constata-se a inexistência de um limite físico para esse espaço (territorialidade), visto que o mesmo é diverso, apresentando diferentes conflitos e interesses.

\section{CONSIDERAÇÕES FINAIS}

Construído para colaborar com a redução do déficit habitacional do município, o empreendimento em estudo constitui-se como um dos exemplos de que a simples oferta de habitações de interesse social pode não solucionar os problemas habitacionais dos municípios, uma vez que podem ser verificados o não cumprimento de diversos aspectos essenciais, como, por exemplo, possibilitar a adequada instalação e fixação dos moradores às moradias; sendo indispensável considerar as particularidades que a habitação de interesse social deve atender para dar resposta à função social.

Faz-se necessário, entre os inúmeros desafios da produção de habitações de interesse social (HIS) no Brasil, a necessidade de compreensão da dinâmica responsável por considerar seus territórios como espaços de vivência e da experiência dos moradores com o entorno dos empreendimentos (SOUZA e PEDON, 2007). Contribuindo para aumentar as chances de acerto nas atividades de planejar e produzir HIS, torna-se essencial a consideração dos aspectos relacionados à construção de novas relações e ordenamento das identidades entre os moradores que vieram de variados lugares e culturas.

Segundo Leitão (2002): “o sentido de pertinência [grifo dos autores] parece ser o elemento-chave no processo de identificação que as pessoas expressam com o espaço em que habitam". Ao observar o Condomínio em estudo, constata-se a existência de um espaço intermediário entre o interior doméstico e a cidade, apresentando-se como um território em disputa, isto é, ainda não socialmente e culturalmente configurado pela nova comunidade em formação. Nesse sentido, ocorreu nesse condomínio um processo que identificamos na teoria como de desterritorialização e está em curso a reterritorialização da comunidade constituída pelo PMCMV, ocasionando um contexto social desarmônico no território fisicamente já configurado e hipoteticamente territorializado para os seus agentes produtores (Estado e construtores), bem como para o senso comum da sociedade que não vive nele e que supõem atender a uma territorialidade em outra escala social (falta de unidade de habitação para baixa renda). Esses territórios necessitam de atenção, visto que são desprovidos de significados, sendo assim, impossibilitados de tornar-se novos referenciais.

\section{AGRADECIMENTOS}

Ao CNPq e à CAPES, pelo apoio recebido.

\section{REFERÊNCIAS}

CABRAL, L. O. A paisagem enquanto fenômeno vivido. Revista Geosul. Florianópolis, v. 5, n. 30, p. 34-45, jul./dez de 2000.

CABRAL, L. O. Revisitando as noções de espaço, lugar, paisagem e território, sob uma perspectiva geográfica. Revista de Ciências Humanas. Florianópolis, v. 41, n. 1 e 2, p. 141155, abr./out; de 2007.

CALISTO, C. S. O ambiente como mundo vivido: uma abordagem do espaço segundo a geografia humanista. 2006. 118 f. Dissertação (Mestrado em Desenvolvimento Sustentável) Centro de Desenvolvimento Sustentável, Universidade de Brasília, Brasília, 2006. 
HAESBAERT, R. Território, cultura e des-territorialização. In: ROSENDAHL, Z.; CORRÊA, R. L. (Orgs.). Religião, identidade e território. Rio de Janeiro, EdUERJ, 2001, p.115-144.

Dos múltiplos territórios à multiterritorialidade. In: CONFERENCE, 2004. Porto Alegre, set. 2004.

HOLZER, W. Uma discussão fenomenológica sobre os conceitos de paisagem e lugar, território e meio ambiente. Revista Território. Ano II, n. 3, p. 77-85, jul./dez. 1997.

Mundo e lugar: ensaio de geografia fenomenológica. In: OLIVEIRA, L.; MARANDOLA JR., E.; HOLZER, W. (Orgs.). Qual o espaço do lugar? 01 ed. São Paulo: Editora Perspectiva, 2012, p. 281-304.

HORA NETO, J. A.; QUEIROZ, J. R. Espaço e Lugar: estudo sobre a compreensão espacial de uma pessoa com deficiência visual. In: Congresso de Pesquisa e Inovação da Rede Norte Nordeste de Educação Tecnológica, 5, Maceió, 2010. Anais... Maceió: CONNEPI, 2010.

LEITÃO, L. Espaço do abrigo? Espaço do afeto! In: DEL RIO, V.; DUARTE, C. R; RHEINGANTZ, P. (Orgs.). Projeto do Lugar: colaboração entre psicologia, arquitetura e urbanismo. 1 ed. Rio de Janeiro: PROARQ, 2002, p. 365-369.

LOPES, J. G. As especificidades de análise do espaço, lugar, paisagem e território na geografia. Revista Geografia Ensino \& Pesquisa. Cascavel, v. 16, n. 2, p. 23-30, maio/ ago. 2012.

MELLO, J. B. F. O Triunfo do Lugar sobre o Espaço. In: OLIVEIRA, L.; MARANDOLA JR., E.; HOLZER, W. (Orgs.). Qual o espaço do lugar? 01 ed. São Paulo: Editora Perspectiva, 2012, p. 33-68.

MINISTÉRIO DAS CIDADES. Avanços e Desafios: Política Nacional de Habitação. Brasília: Ministério das Cidades, 2010.96 p.

PALERMO, C. Sustentabilidade Social do Habitar. 1 ed. Florianópolis: Ed. da autora, 2009. $96 \mathrm{p}$.

PREFEITURA DE JUIZ DE FORA. Plano Diretor de Desenvolvimento Urbano. Juiz de Fora: PJF, 2000. Disponível em: <http://www.pjf.mg.gov.br/pddu/>. Acesso em: fev., 2014.

RELPH, E. Reflexões sobre a emergência, aspectos e essência de lugar. In: OLIVEIRA, L.; MARANDOLA JR., E.; HOLZER, W. (Orgs.). Qual o espaço do lugar? 01 ed. São Paulo: Editora Perspectiva, 2012, p. 17-32.

SOUZA, E. A; PEDON, N. R. Território e Identidade. Revista Eletrônica da Associação dos Geógrafos Brasileiros. Três Lagoas - MS, v.1, n.6, ano 4, p. 126-148, nov. 2007.

TUAN, Y. Espaço e lugar: a perspectiva da experiência. 01 ed. Londrina: Eduel, 2013. 248 p.

VIGLIECCA, H. Palestra sobre projetos arquitetônicos, urbanísticos e tecnologias. In: CONGRESSO INTERNACIONAL DE SUSTENTABILIDADE E HABITAÇÃO DE INTERESSE SOCIAL. 3, 2014. Porto Alegre. 